\title{
A Note on Transliteration
}

There is no consensus among scholars as to how modern Greek should be transliterated into English. I tried here to present words so that non-Greek speakers will be able more or less to pronounce them, and Greek speakers will be able to recognize them. Because the meaning and sound of some Greek words and prefixes will be already familiar to non-Greek speakers, my transliteration is not entirely consistent. I tried on occasion to preserve the familiar English spellings of borrowed prefixes: thus polyteknes (having many children), rather than politeknes. When quoting from English sources, I kept Greek transliterations as originally published: hence both Mestheneos and Mesteneos. Generally speaking, I used $d h$ for $\delta$ (pronounced like the th in the) and $k s$ for $\xi$, while $\chi$ became either $h$ or $c h$, depending on which seemed more appropriate. Similarly, $\gamma$ may be $y$ or $g$ or $g h$. The accent mark indicates emphasis. Personal and place-names are not made to conform to my transliteration system. 
This page intentionally left blank 